\title{
Papers
}

\section{Stress tests and their contribution to financial stability}

\author{
Antonio Marcelo, Adolfo Rodríguez and Carlos Trucharte*
}

*Banco de España (Bank of Spain), Alcalá 48; 28420 Madrid, Spain

tel: + 3491338 4215; fax + 3491338 6140; e-mail: carlostrucharte@ bde.es

Antonio Marcelo is an economist at Bank of Spain in the Banking Supervision Department. $\mathrm{He}$ is an expert of credit risk models validation (Basel II) and stress testing.

Adolfo Rodríguez is a bank examiner at Bank of Spain in the Banking Supervision Department. He is an expert of accounting, banking financial information, stress testing and crisis management.

Carlos Trucharte is an economist at Bank of Spain in the Banking Supervision Department. $\mathrm{He}$ is an expert of stress testing and crisis management.

\footnotetext{
Abstract

One of the main responsibilities of the relevant supervisory authority is to ensure a sound, stable and efficient financial system. An essential part of the stability and efficiency of a financial system depends on those same facets of the banking system, which are based on prudential regulation and effective supervision. The progressive implementation of stress tests as a tool complementing traditional supervisory practices is making them increasingly valuable to financial authorities in monitoring and safeguarding the stability of the financial environment. The increasing use of stress tests highlights the need to establish basic principles and guidelines providing for a systematic approach to them that is rigorous and straightforward. This paper is intended to offer those
}

guidelines. In essence, it reviews the most representative features of stress exercises. It also explains stress test methodology, basically how to set up and carry out an exercise appropriate for the structure, complexity and risk profile of the system under examination. A general conclusion is drawn on the significance this tool will, for various reasons, have in the near future. Journal of Banking Regulation (2008) 9, 65-81. doi:10.1057/jbr.2008.1

\section{INTRODUCTION}

Although there is no generally accepted definition of financial stability, it can basically be taken to mean that state which, for a given economy, provides sufficient assurance that the efficiency of intermediation between the suppliers and demanders of funds (broadly speaking, between investors and savers) will not be significantly affected by adverse events (shocks). Clearly, the financial authorities, as those to which powers in this area have been delegated, have a particular and well-defined interest in maintaining that stability.

As just noted above, one of the basic responsibilities of a central bank or the relevant supervisory authority is to ensure a sound, stable and efficient financial market which safeguards the interests of the diverse agents participating in it, thereby enabling them to operate with full confidence. Financial stability is an end in itself and also a means of guaranteeing a suitable financial environment (wide access to financial 
services) and achieving sustained and balanced economic growth in both industrialised countries and emerging economies.

The stability of the financial system as a whole hinges essentially on that of the banking system; and a mainstay of efficiency in channelling the flow of saving between investors and savers within the banking sector is the existence of a prudential regulation and an effective supervision that adequately complement each other. The former should provide the basis and the appropriate legal structure so that credit institutions can accurately assess the financial risks they incur. The latter must ensure that banks observe the rules, standards and codes of prudence that provide them with appropriate levels in the key variables underpinning and, ultimately, determining their financial condition (profitability and solvency).

It is in regard to effective supervision that stress tests can be most useful. Their development and progressive implementation as a prudential technique complementing traditional supervisory practices are making them increasingly valuable to supervisory authorities in monitoring and protecting the stability of the financial environment. Regular stress testing should provide a more reliable and accurate assessment of the possible impact of adverse shocks in the form of extreme movements in variables liable to affect the economic setting and the main determinants of the stability, and therefore the soundness of the financial system. Consequently, stress tests should be regarded as a supplementary tool of supervisory activity able to provide firm and certain criteria for the proactive and reactive measures to be taken to cope with the estimated impact of a predefined shock to the system.

Just as this type of exercise has become important for supervisory authorities at overall financial system level, it has become similarly valuable for banks at the individual level. In their search for better ways to control their risks (management, measurement and mitigation), banks have started to subject their different business areas to stress tests in order to determine, first, the possible impact of shocks liable to affect their financial condition and, secondly, how sensitive their various types of risk are to these adverse shocks. In other words, the aim is to be able to define their risk profile more precisely.

This deeper knowledge makes it possible for credit institutions to pursue management policies more attuned to the risks they run, allocate better the funds raised by them and improve the quality of their business in anticipation of possible unfavourable shocks. In the medium term, this will also have implications for the stability of a financial system, enhancing its soundness and contributing to more efficient financial intermediation, all of which will make for improved overall allocation of the resources of the economy, ultimately with the resulting positive impact on social welfare.

The progressive use of stress tests will foreseeably help banks and financial authorities to understand better the consequences of possible future events and, in particular, to assess their impact more accurately. This will have to be achieved by a commitment to step up the development of these tests and raise their accessibility and frequency of use, both by the more specialised and active institutions and by others focused on more traditional types of business, while avoiding over-simplification of the exercise or a mere description of routine processes that has no subsequent utility.

Therefore, stress tests should be seen as a way of looking at the more common banking risks that enhances the perception of them. This includes an accurate assessment of how those risks may be influenced by certain extreme situations, both for individual institutions and for the system as a whole. The aim is to anticipate the impact of difficult situations, whatever their origin, potentially able to alter the stability desired by the supervisory authority. Consequently, an estimate can be made of the resilience that the banking system will show if certain hypothetical shocks crystallise and become real events. Hence, the results of stress 
tests can and should: (1) add value to the internal control exercised by banks in the course of risk management, (2) serve as a basis for fostering prudential techniques of protection against adverse situations, and (3) facilitate prevention and early warning and response tasks to deal with these adverse situations.

In short, these tests should be viewed as an additional resource available for prudential banking supervision or, indeed, for helping to make economic agents aware of measures to be taken or changes required to preserve the desired financial stability. For the supervisory authority, they should also represent an exercise in self-discipline (review of its mandate) and in scrutiny (analysis and assessment of the quality of its work) by the other economic agents of its responsibility to strengthen and safeguard the smooth working of the financial system.

In recent years the design and implementation of stress tests have taken on particular importance for various reasons. One is the recommendation to run them regularly since they have been assigned a major role in the programme to assess the stability of international financial systems in both developed and emerging economies. This programme, which is sponsored by the International Monetary Fund (IMF), ${ }^{2}$ uses the 'Financial System Assessment Program' (FSAP) methodology developed by the IMF and the World Bank. That recommendation, along with the reasons mentioned above in relation to financial stability, highlights the need to establish a series of basic principles and guidelines for a systematic approach to stress tests in the most rigorous and, at the same time, simplest possible way. This paper is intended to offer those guidelines.

In this vein, the next section briefly describes the most representative features of stress exercises and the types most frequently used in practice. The subsequent section, then explains stress test methodology in depth. It is presented, in indicative terms, as a practical guide on how to set up and carry out an exercise appropriate for the structure, complexity and risk profile of the system under examination. Additionally, a fairly detailed description is given of how to interpret the results obtained, which will be used to determine the resilience and soundness of the system. Finally, a conclusion is drawn on the significance this tool will, for various reasons, have in the near future.

\section{STRESS TESTS: DESCRIPTION AND TYPES}

A stress test is usually defined as a set of techniques, tools or, in general, procedures used by either individual institutions or supervisory authorities to gauge as objectively as possible the financial condition of the system under examination. These tests aim not only to identify possible vulnerabilities (expressed in the form of adverse shocks) liable to affect the financial situation of a certain institution or financial system but also to estimate and evaluate as accurately as possible the quantitative impact of those shocks. In short, the objective is to test the stability and resilience of the system or institution being assessed and analysed.

It is generally accepted that carrying out any stress test normally involves the following stages:

1. Delimitation of the scope of application of the test.

2. Definition, design and calibration of the shocks with which the system under examination is to be stressed.

3. Estimation of the impact of the shocks chosen and quantification of that impact in terms of variables determining the financial condition of the system to be tested.

4. Identification of the possible considerations and policy measures deriving from the results obtained in point 3 above.

Let us look first at the scope of application. This will depend on what implications are to be drawn from the stress test, which is basically a matter of how specific or general it is desired to make it. Tests of a general nature (broadly speaking, macro-tests) encompass the analysis of the greater part of the financial system, or at least that of its most significant components. 
Their objective is therefore to test the resilience and stability of the financial system as a whole.

In this type of exercise, either the system can be treated at aggregate level, so that in order to subsequently descend to individual-institution level, the results obtained are applied to each separate component of the system (top-down approach), or else a sufficiently representative number of financial institutions is chosen (by size or by type of business) and the stress test is conducted on them and the results obtained are raised to total system level (bottom-up approach).

There is another type of stress tests of a much more specific nature. This is carried out at individual level (micro-test) and the analysis relates to one particular financial institution (or a very small group of them). A more specific form is that which, within each institution, focuses on one or more portfolios which, because of their relative importance, it is wished to analyse.

The second stage of a stress test consists of establishing the shocks that may negatively affect the stability of the system being tested and with respect to which the system's soundness and resilience is to be checked. The process of characterising the shocks to be considered consists in turn of various sub-stages.

First, the type of shock to be considered must be determined (identification and definition). Subsequently, it is calibrated (the size of the shock to be considered is specified) and then implemented (introduction into the system and quantification of its impact).

The shock is chosen on the basis of the risks to be measured, it is calibrated according to the type of analysis to be conducted and it is implemented using the main variables (certain specific key parameters) that, due to their nature and availability, have the most significant direct or indirect effect on those risks.

Additionally, this second stage involves different aspects that must be taken into account because, in one way or another, they influence both the implementation and the result of the stage. In general, depending on the number of variables shocked, the following are usually distinguished:

- Sensitivity analysis. A single variable is shocked and the result obtained is subject to the condition that the other system variables remain unchanged.

- Scenario analysis. A broad group of variables is changed en bloc, thereby defining the socalled stress scenario on which the stress test is based.

Depending on the analysis to be conducted, the next step in this stage is to determine the size of the shock (shock calibration) with which it is desired to carry out the stress exercise.

In sensitivity analysis, the usual practice is historical calibration, under which the size of the shock is chosen according to the largest change that the variable to be shocked has undergone during a certain time period. The choice of this time period is closely related to the type of risk being analysed and to the market circumstances prevailing over that period. The periods are generally between 20 and 30 years, although in the case of certain variables lacking historical depth, ${ }^{4}$ this interval may be limited to 10 or 15 years.

An alternative approach is to obtain the distribution of the observed largest changes and, having chosen an extreme percentile or a certain probability of occurrence (adverse end of the tail of the distribution), determine what value the variable would have in a stress situation. In addition to these approaches, on certain occasions use can be made of hypothetical calibration, that is, setting a value for the shock based on a certain assumption that need not have been observed in the past.

In scenario analysis, the best way of determining the variations in a broad set of variables is to use an econometric model. Based on the relationships established in the model, an ad hoc change (hypothetical, historical, or probabilistic calibration or a combination of these) in one of the variables included in it 
triggers a chain reaction of changes in the value of the other variables of the model, thereby creating the desired stress scenario.

The third stage of a stress test is to specifically estimate the impact of each shock. In this stage it must be decided how the shocks defined and calibrated in the previous stage are to be included in the system, that is a quantitative assessment is to be made of the impact on the system's financial condition, so that its resilience to the shocks used can be evaluated.

Whatever the type of analysis and calibration used, the impact of a shock can be estimated in two different ways:

- Piecewise approach

- Integrated approach

The first consists of choosing, in isolation from the others, certain key variables that directly affect the financial condition of the system analysed (here the term 'variables' is used broadly and can include, eg, a certain portfolio or some of its components) and estimating how they change in response to the defined shock. The stress test thus consists of determining separately the size of the change in these key variables in a stress scenario with respect to their value in a scenario of stability (baseline scenario) and then expressing those changes in terms of the variables that determine the financial condition of the system under examination (generally profitability and solvency).

Under the second approach, the impact of a shock is estimated on an integrated basis taking into account all the possible risks prone to be affected by that shock; these are captured by estimating the aggregate distribution of losses in each scenario. If sufficient data were available on, and an accurate calculation could be made of, the correlations between the different risks faced by financial institutions (basically market, interest rate, credit, liquidity and business risk), aggregating them would yield the exact effect that the shock in question would have on the financial condition of the institutions or of the system in general.
However, when data availability is severely limited and an accurate calculation of correlations between the different types of risk is difficult to make, the piecewise approach is adopted and, should various risks be affected by the same shock, they would be grouped in a basically additive manner.

Finally, as a corollary of the previous stages and once the impact on and estimated resilience of the system have been determined from the results of the stress exercise, the need arises to consider what measures will help the smooth working, efficiency and continued stability of the system under examination. If major weaknesses have been detected and remedying them is a priority, it will be necessary to focus on revising, adjusting and strengthening the existing prudential elements currently in place.

\section{STRESS TESTS: METHODOLOGY AND PRACTICAL APPLICATION}

This section takes a practical look at how to go about a stress exercise at overall level (macrotest) when the scope of application is the system as a whole. It is intended to serve as a model for how to approach stress testing and as a practical guide to stress testing that will be of use to any central bank or supervisory authority considering this type of exercise in its task of assessing potential risks and their impact on financial system stability.

As just mentioned above, the scope of application of this type of stress test is the financial system as a whole, although on certain occasions, and depending on the type of analysis or risk, the scope may be confined to the most significant part of the system ${ }^{7}$ and, within that part, to a specific group of representative institutions (chosen either for their size or type of business) based on their importance within the system.

The kind of approach (top-down or bottom-up) to be used in the stress test will be primarily determined by the availability of data to the supervisory authority. Both approaches have strengths and weaknesses. 
From the supervisory standpoint, the topdown approach calls for a stress test structure that is both common (in terms of tools and methodology) and standard (applied identically to all participating entities). This normalised structure allows a test to be defined which is applied coherently and consistently regardless of the type and number of banks taking part in it. The use of a proprietary and joint framework applied uniformly for all participants yields results free from the arbitrariness and heterogeneity caused by internal differences in the methodology, calculations, importance and type of business of each individual institution.

The main weakness of this approach coincides with the main strength of the bottom-up alternative: the richness of the individual information and the level of detail available to institutions, which enables a much more accurate perception (specific characteristics of their risk profile) of the impact that a particular shock would have. This greater level of detail, as compared with the uniformity of the common method, is the trade-off that must be weighed up when deciding which approach to use.

The most complete stress exercise would undoubtedly be one in which the data available to the supervisory authority and to the individual institutions are fairly similar (eg via regular reporting by the latter). The exercise would be carried out by the authority (topdown approach) for the system as a whole. Simultaneously, the participating banks would carry out exactly the same type of test (the same assumptions and shocks) as the supervisor. These results would then be aggregated (bottom-up approach) and examined for convergence between those obtained in one and the other approach. Ideally it would be found that the exercise carried out by the authority replicates the results reported by the individual institutions using their own methodology.

As noted in the previous section, a stress exercise generally involves two types of analysis: one looks at sensitivity and the other at scenarios.

\section{Sensitivity analysis}

Sensitivity analysis seeks to estimate how the main determinants of the financial condition of credit institutions are impacted by certain oneoff shocks to specific risk factors of bank portfolios. Sensitivity exercises centre mainly on the analysis of market, interest rate, credit and liquidity risk.

\section{Market risk}

Market risk typically appears in the trading book of banks (scope of application) and changes in the key parameters of this portfolio determine the type of analysis to be conducted. The variables identified to carry out stress exercises on the trading book and that are normally subjected to shock are: short- and long-term interest rates, stock market indices and prices, volatilities, credit spreads and exchange rates.

Given that, in general, data are available for the variables that are usually subjected to stress, the size of the shock to the variables is usually determined by using historical calibration. The impact of shocks on a bank's financial condition is usually measured in terms of profits (by determining the change in the economic value of the portfolio resulting from a shock and expressing this change in terms of the consolidated profit) and of solvency (change, measured in percentage points, in the capital ratio due to the variation in the economic value of the trading book, via impact on profits, as a result of a shock).

An additional measure used for analysing the impact of a shock is the $\mathrm{VaR}$ (value at risk) of the trading book. It allows the actual risk due to a shock to be gauged more exactly and related to the amount of regulatory capital allocated to the trading book, thereby indicating whether or not the shock calibrated for the chosen variable could have a significant impact on the institution's solvency.

\section{Interest rate risk}

Interest rate risk arises from the exposure of a bank's financial structure to adverse movements 
in interest rates. The asset and liability maturity structure and the possible hedges used are fundamental in determining the outcome of the exercise. The day-to-day asset and liability management of banks faced with uncertain interest rate movements generally provides sufficient methodology and tools to measure and analyse this risk.

The scope of application of a stress exercise for this risk is typically an institution's balance sheet. The shocks generally used consist of shifts, parallel or otherwise, in the yield curve. The impact of the shocks is estimated by measuring the resulting change in economic value and its impact on capital (tier 1 and tier 2).

\section{Credit risk}

For credit risk, the scope of application of the sensitivity analysis is determined by the banks' loan portfolio. The analysis of this type of risk is much less developed than that of the two mentioned above, basically because of the lesser availability of data. Despite this lack of data, given the weight and importance of the loan portfolio in banks' balance sheets, the analysis of credit risk should be given greater importance than it has had to date in stress exercises.

Stress tests for this type of risk should begin by distinguishing between portfolios (different asset types), for example, a differentiation between risk exposures to firms and individuals (within the latter, mortgage loans should be distinguished from the rest, basically consumer credit). This separation enables the specific design, calibration and final impact of the shock in question to be determined adequately. The reasons why this distinction seems to be unavoidable are set forth below.

First, a particular shock may have a different impact (to the point of having or not having an effect) depending on the portfolio considered Secondly, given a shock, it seems clear that the sensitivity of each type of asset to the key parameters determining credit risk is different, and the intensity of the impact also differs depending on the idiosyncratic characteristics of each borrower. And finally, given the different levels in the values of the risk parameters that characterise each portfolio, it is absolutely necessary to distinguish between them so that the amount of shock can be accurately determined for calibration purposes.

The key parameters in credit risk analysis are basically probability of default (PD), LGD and exposure at default (EAD). ${ }^{10}$ Determining the amount of the shock to which they are to be subjected is the next step in the sensitivity exercise for this particular risk.

So far, stressing the PD has entailed increasing it by a predetermined amount. To do this, generally the credit quality of all borrowers is worsened by one or two risk categories (downgrading). The customary procedure for LGD is to assume an ad hoc increase by a given percentage thereof or to define some kind of range of variation and use it to calculate the change in credit risk. As regards EAD, on which little work has been done to date, its stress will move in unison with that of PD and LGD. Hence, the shock would consist of assuming an increase in these last two parameters, together with a possible increase in credit line drawdowns by borrowers.

This approach, however, is arbitrary in regard to determining the change stipulated for the risk factors, and should therefore be further developed along the same lines indicated in the analysis of market risk and interest rate risk. That is to say, the size of the shock chosen should be determined by carrying out a calibration that takes into account the availability of historical data, although in this case a major restriction is the lack of depth of the databases for adequately calibrating the shock. In any event, as noted above, the disparate behaviour of the risk parameters of the various portfolios (both their levels and their rates of change) would require a separate calibration of the shock for each type of asset considered.

This calibration is based on the distribution of the observed maximum historical variations (where appropriate, an increase in value). Based on this distribution and for a certain probability of occurrence (eg 1 per cent), the amount of 
the change proposed as a shock is determined, both as a percentage and in absolute terms of the levels of the PD, LGD and EAD series. In this way, the maximum change recorded will coincide with the worst point of the cycle (recession, if that is the case) and as a result, will be influenced by the macroeconomic environment which typically characterises these periods of crisis (negative growth of activity, higher interest rates, correction of house prices in real terms, etc).

Under these conditions, it can be argued that the largest change observed in a sufficiently long period of time would represent a case of stress. It should, however, be noted that not only the changes in the risk factors but also their absolute levels, clearly depend on the underlying economic environment at any time in the observation period considered. Hence this calibrated change has to be adjusted to the current period, that is, relativised to the levels of the risk parameters prevailing in the economic environment at the time for which the stress exercise is carried out. This must be done because although in a recession a shock may represent a certain percentage increase in the level of a risk parameter, in an upturn that percentage may correspond to practically no change in the value (level) of that parameter.

To this end, we propose that the observed historical change be converted to percentage points. The shock would thus be expressed as a percentage-point increase in the current value of each risk parameter. This increase would be equal to the percentage points corresponding to the largest observed change (or to the change corresponding to a given probability of occurrence in the distribution of recorded variations).

As an alternative method, the value of the shock may be defined as the largest historically observed value of the risk parameters and applied to their current levels. However, such a situation would be highly improbable if the current levels are far from their historical highs. A valid approach to this option might be to observe the number of periods needed in the past to reach those highs (number of periods elapsed from the cyclical downturn to the most adverse economic situation). Once that number of periods was known, the observed largest change would be apportioned among the number of periods elapsed until the historical high was reached.

Nevertheless, this approach has a major and rather intractable limitation which, in addition, coincides with the main problem in sensitivity analysis: that of holding unchanged the setting in which the risk parameters vary whenever that setting encompasses more than one period. This is difficult to reconcile with a dynamic economic environment where financial institutions react quickly to adverse situations by adjusting their activity and business structure. In other words, the assumption that the PD and LGD increase up to a certain level over a number of periods, while the composition of the different portfolios, the volume of credit, the funds received, the profits earned, etc are held constant is a constraint that is too difficult to justify.

As with the other risks described above, once the shock and its size have been determined, its impact on the financial condition of the system is estimated with the final aim of testing the system's resilience. This is done by assessing that impact on profits and solvency. The effect on profits is determined directly from the variation in the expected loss derived from the estimated change in the PD and LGD and, where applicable, from the exposure to be considered. A larger loss means a direct impact on profits due to the need to recognise a higher volume of impairment losses.

The impact on solvency is calculated similarly. The change in the capital ratio is determined from the estimated change in the expected loss: lower profits and, therefore, less likelihood of an increase in reserves and, where applicable, also a change in the possibility of recognising provisions as eligible capital for regulatory purposes. Figure 1 summarises, visually, the approach followed in the analysis of credit risk. 


\section{Sensitivity Analysis Diagram}

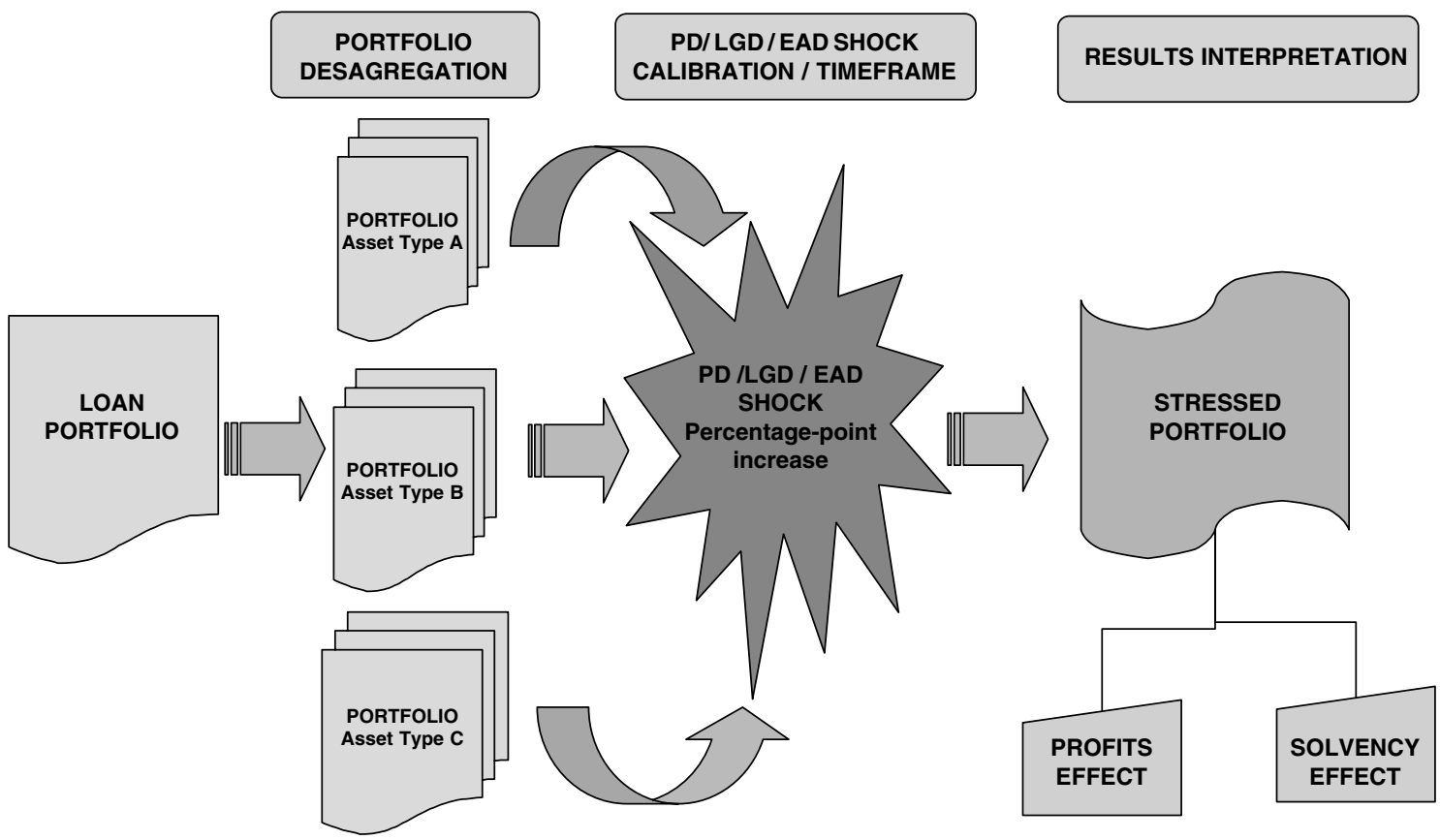

Figure 1 Sensitivity analysis: credit risk

\section{Liquidity risk}

Standing midway between sensitivity analysis and scenario analysis is the assessment of liquidity risk. The design of a stress test of liquidity risk is difficult to state in formal terms because it largely depends on the baseline scenario to be subjected to shock and on the availability of data with which to work.

First, a liquidity stress test can be either static or dynamic: it can focus solely on the assessment of liquid assets with respect to a certain parameter at a given date, or it can be enriched with the maturity gaps of asset and liability positions, or it can go further and consider the cash flows (inflows and outflows) expected for different periods.

Also, it is fundamental to define the circumstances in which the exercise will be set and the shock to which the institutions' liquidity will be subjected. This may be done, for example, as follows: establish a situation of normality in which a component is stressed, such as the ability to liquidate at will certain asset positions or the need to face a certain outflow of funds; or else, simulate a stress scenario in which all the factors relating to liquidity are modified for a certain period and analyse the institution's resilience to a significant change in one specific factor.

Particularly important in this respect is the stress assumption under which the analysis is conducted. From a macroeconomic standpoint, this could be a liquidity stress that poses operational problems in the interbank market or in the wholesale payment systems, or, otherwise, the exercise could focus on stress in the particular conditions of a single bank. The first, unquestionably of interest, presents a complexity that in certain cases goes beyond the scope of a pure liquidity analysis in the strict sense and touches on the field of operational risk and on the responsibility of the authorities for arranging contingency plans to enable these systems to work smoothly. The second, however, is easier to define and check, as well as being more suitable for assessing the 
management ability of banks in dealing with problems that do not exceed their management responsibility.

The object of analysis can also be the liquidity of a specific institution or of the system as a whole, assuming a macroeconomic environment with a structural lack of liquidity which occasionally produces tension in the markets in general or in a particularly vulnerable institution given its particular financial condition. However, in this case delimiting the geographical and time scope of the stress test is more difficult and calls for a greater knowledge of the behaviour of the other economic agents and of how the monetary policy of each country or economic area responds to the situation under examination.

For the case at hand, we propose an approach to liquidity stress that particularly takes into account and affects individual institutions. It assesses their resilience in a stress situation based solely on their ability to raise and manage liquid funds. Evidently, if the analysis can be conducted on a significant set of institutions within the financial system, the authorities will be able to test the overall system's robustness in an episode similar to that in mind when the exercise was designed.

With regard to the practical aspects of carrying out this analysis, the liquidity exercises conducted so far in the stress tests reported in the extant literature have basically taken a static approach, although they have attempted to add a dynamic component by analysing the ratio of liquid assets to certain liabilities at different dates or by considering residual maturities for certain assets and liabilities. This paper seeks to go one step further as it is proposed to analyse institutions' liquidity by assessing real cash flows over a certain period under stress circumstances that affect assets and liabilities taken as a whole.

Specifically, let us suppose a situation in which there is a loss of confidence in an institution. In one instance it lasts one week, and in another, one month. Also, the institution has to meet liquidity needs in these two periods under the assumption that its activities have to be kept on a fairly normal footing and that extraordinary recourse to the central bank is not possible.

Recourse to the central bank is limited to normal access based on its customary relationship and on the assets accepted as collateral to raise funds; the need to preserve a similar pattern of activity is based on the premise that the lack of confidence is not due to an actual deterioration of the bank's financial condition and that it therefore shows no signs of imminent crisis. In other words, the lack of confidence may be caused by rumours from various sources that, in principle, are unrelated to any solvency problem.

On this basis we will analyse, in particular, some of the factors that influence the cash flows in these periods. Given that there is a crisis of confidence, we consider that attention should focus primarily on the behaviour of demand deposits, on the grounds that, in this case, it would be the most sensitive item on the balance sheet. Hence, based on the estimated cash flows, an assessment will be made of how large an outflow of demand deposits (factor subjected to shock) can be withstood by a bank.

The methodology used, which is an adaptation of the approach developed by the Financial Service Authority (FSA) of the $\mathrm{UK}$, is intended to estimate the real cash flows for the stress periods considered, independently of those required for the bank's normal day-today business. These flows are therefore not based solely on asset and liability maturity gaps, but incorporate also the stress situation in which the institution is being assessed and the shock level set for demand deposits.

To calibrate the shock applicable to demand deposits, two approaches may be considered: a historical change in demand deposits in general terms or a change in those of banks in crisis.

In this respect it should be taken into account that although data will not normally be available on deposit run-off, deposit outflows are usually due to depositors' sensitivity to their return on investment. However, for institutions that have not had any problems in 
the period for which there are financial data, it seems reasonable to use a distribution function of the changes in deposit balances and set an appropriate percentile (eg the 99th percentile) that represents a larger change than the historical experience. To improve this calibration, it should be compared, if possible, with crisis episodes that banks have gone through in the past, naturally taking into account their nature and extent so as not to distort the meaning and design of the stress test.

This exercise will include analysis of the availability of liquid assets for the predefined time horizon and, consequently, will entail a review of banks' contingency plans. Given that in most cases the starting point will be the information contained in an institution's balance sheet at a fixed date, stressing the institution's liquid position will require the following. First the maturity distribution of the different instruments over the time-frame of the exercise must be known. This makes it possible to estimate how the different asset and liability positions can be renewed. Secondly, haircuts must be considered in the sale or transfer of every financial asset, not only in normal market situations but also under the specific stress scenario in question. Thirdly, the various cash inflows and outflows that are not included in the balance sheet position have to be estimated as well. And finally, a realistic statement of alternative sources of liquidity (bond issuance or access to securitisation) has to be explicitly made. As noted before, the exercise assumes that each institution must keep (to the maximum possible extent) to its normal day-to-day activity.

The ultimate goal will be to calculate a liquidity ratio (liquidity inflow/outflow for periods of one week and one month) that enables an accurate assessment of the ability of institutions to respond to a defined shock. The composition and relative importance of the estimated cash flows, as well as the financial situation of the bank at the end of the test, must be analysed in order to properly interpret the liquidity ratio obtained.
Nonetheless, this methodology is flexible enough to be used also to analyse the response to a stress situation. This involves establishing ex post constraints on one or more factors that influence the liquidity situation, such as: difficulty in liquidating assets in certain markets, access to interbank financing, or, in general, an inability to make use of an alternative liquidity source. Having said this, it should be pointed out that setting an ex post constraint introduces a distortion that may, in certain cases, invalidate the interpretation of the result obtained, since, if the constraint had been established beforehand, the bank's response might have been different.

\section{Scenario analysis}

\section{Stress test design}

Unlike sensitivity analysis, scenario analysis is not based on specific shocks to a single variable or small group of variables (eg the determinants of credit risk) while holding unchanged the other variables comprising the reference economic setting of the exercise. Rather, econometric models are generally used to estimate how the main macroeconomic and financial aggregates of the system would be affected in a certain stress scenario. Thus scenario analysis seeks to estimate how a particular scenario affects the key variables that determine the financial condition of the system under analysis and hence its possible impact on the system's stability.

Additionally, the time horizon considered is usually longer than that used for sensitivity analysis, covering at least one full business year. Moreover, given that it is macroeconomic variables that are being subjected to shock, their effect on the financial condition of banks can be expected to extend beyond one year. Therefore, the analysis period to be considered in the case of scenarios should be two or three business years. We feel that this is sufficient time for the consequences of those shocks to fully crystallise, without an excessive loss of reliability in the estimates. 
In any event, the availability of data will be what will decide the robustness of the analysis and whether the exercise can be conducted for the total system by the supervisory authority and, at the same time, individually by the institutions participating in the exercise.

For scenario analysis, this paper introduces various new features not seen in traditional analyses reported in previous studies of stress exercises. They basically concern the scope of application of the analysis and the need to distinguish between business risk and credit risk.

We propose that the scope of application of this type of analysis should be both the balance sheet and the profit and loss account of banks. Depending on the approach chosen, these financial statements would be either those of the system as a whole or those of participating institutions.

We consider that the role of modelling in scenario analysis should not be reduced to estimating a single equation that, as usually occurs, is the bottom line of the profit and loss account; rather it should be developed further so as to provide a more comprehensive breakdown that distinguishes different balance sheet items and their contribution to the profit and loss account (ie the various asset and liability groups and their associated returns), as well as other elements of the profit and loss account. All this considerably enriches the exercise in that it enables step-by-step monitoring of the various items comprising a bank's main activities and operations. As a result, clarity is improved and the sensitivity of institutions' activity to a shock is assessed more accurately (in both direction and intensity). ${ }^{13}$ Basing the analysis only on the bottom line of the profit and loss account carries the danger of leaving certain effects concealed that individually may be very significant for certain balance sheet groupings (or for their contribution to the profit and loss account), thereby influencing and altering the interpretation of the banks' risk profile.

As has just been noted, distinct balance sheet items show differing sensitivities to certain shocks and they may also vary by different amounts in response to changes in the value of certain macroeconomic variables. Thus, for instance, interbank financing positions and equity respond differently to, for example, a scenario of falling stock market prices; or credit growth and, for example, fee and commission income respond differently to an economic recession deriving from a stress scenario of contraction in domestic demand; or the interest rates on loans will rise faster and more sharply than those on deposits in a scenario of across-the-board interest rate hikes.

As a result, under the stress conditions defined in each scenario, the profit and loss account should thus be derived as the direct algebraic sum of the contributions of the stressed asset accounts less the related liability accounts, plus those of another series of profit and loss account items clearly dependent on economic activity and hence on the main macroeconomic and financial variables, such as fees and commissions, operating expenses and provisioning charges (impairment losses). In this way the contribution of each of these components to the final profit figure can be precisely determined and the true impact of each stress scenario on the financial condition of the system analysed can be assessed more exactly.

As noted above, another proposal made in this paper is that the measurement of the effect of the change in the macroeconomic conditions included in each stressed scenario and its final impact on the key risk variables determining the economic condition of the system, should be made and analysed by separately breaking down the business risk, on the one hand, and credit risk, on the other. Specifically, the impact of the shocks chosen to stress the banking system will directly affect the system's financial condition through the banks' balance sheet (business risk) and indirectly affect it through the financial health of their borrowers (credit risk).

Business risk, as stated above, is measured by simulating the balance sheet and profit and loss 
account of the total system (or those of each individual bank), first under the conditions of a baseline scenario and then under those set in each stress scenario. This simulation consists of estimating certain balance sheet groupings, their implicit return and certain profit and loss account components. To do this, use is generally made of econometric models, accompanied in the case of individual institutions by estimates based on internal control budgets and management information coming from their own in-house modelling framework. First, the balance sheet and profit and loss account for the baseline scenario would be prepared; then they would be stressed according to the chosen scenarios.

Regarding the impact on credit risk (via borrowers' creditworthiness), the approach proposed here is also different from that of other studies, which usually consists of estimating an equation for credit loss provisions (based on macro and financial variables) ${ }^{14}$ and using those estimates to adjust the bottom part of the profit and loss account. The basic weakness of this approach is the arbitrariness and lack of uniformity at international level in the regulation and application of the provisioning systems.

To overcome these problems and measure more exactly the credit quality of banks' borrowers (measure their credit risk and include it in scenario analysis), we propose the use, and therefore the modelling, of their probability of default. The reason for this decision is based on the fact that this parameter is the measure generally used by banks in their internal models to evaluate and manage credit risk. It is also the basic reference parameter for the supervisory authorities in assessing this risk.

We thus propose that the estimated change in credit loss provisions under each stress scenario be driven and, ultimately, determined by the change in the expected loss resulting from variations in the PD due to shocks to the economic variables used in each scenario.

The parameterisation of the PD entails the development of a statistical model to relate it to different factors, some of which must be macroeconomic and financial system variables, which, for each shock scenario, serve to alter the PD and include the stress condition in the credit risk.

Our suggestion is thus to relate the macroeconomic environment to credit risk via PD and, in short, express this parameter in terms of variables such as economic activity, the unemployment rate, interest rates or any other likely to affect bank borrowers' debt service capacity. ${ }^{16}$ This would yield a cyclical PD dependent on the economic conditions of each scenario. The full pass-through of a stress scenario to credit risk will be achieved once LGD and, where applicable, EAD can also be expressed in terms of macroeconomic variables as described for the probability of default. For example, for modelling purposes changes in loan to value ratios, real estate prices or interest rates directly affect the value of LGD.

Once the stressed values of the risk parameters are known, the stressed expected losses associated with each scenario can be found immediately, and this determines the volume of provisions to be set aside by banks to meet those losses and, finally, their impact on the profit and loss account.

The possibility of using this approach will be determined by the extent to which institutions have developed their own internal models for risk management and measurement (specifically, that for credit) and by the availability to the supervisory authority of some type of borrower credit quality classification system to enable it to obtain the PD, LGD and EAD values needed to calculate, on an overall basis, the impact of the relevant scenario.

A remaining challenge in scenario analysis is to take into account second-round and feedback effects not usually addressed in this type of stress exercise. The proper way to take them on board is to formulate a multi-equational model that totally captures the intrinsic interrelations between the real and the financial sector. As mentioned above, in scenario analysis described so far, shocks only move in one direction. 
A complete analysis of their total impact, however, should reflect the amplified effects on the financial system once the initial consequences of the original impact are reintroduced into the macro model equations of the real sector.

To illustrate this, let us take a simplified example: assume a scenario of zero growth in economic activity. This, among other effects, will induce a decrease in the credit quality of banks' borrowers (increase in credit risk). Banks will react by cutting back on new lending, which will clearly affect economic agents (basically households' and firms' borrowing capacity), aggravating the initial general economic situation and therefore amplifying the original shock. The initial scenario of zero growth will worsen, turning into one of negative growth, which obviously will affect obligors' credit quality more adversely than initially. The convergence mechanisms of the multi-equational model would eventually bring the feedback process to an end and the total amount of the shock would be fully determined.

The dynamics of the effects described so far seem, in principle, easy to understand. However, the complicated relations between the financial and the real sector are hard to define and accurately estimate. Nevertheless, a very simplistic approach could be used to approximately evaluate these feedback effects. This would consist of amplifying, to some extent, the initial amount of shock coming from the originally predefined stressed scenario. That increase must be large enough to account for the additional impact that feedback effects would have on the financial system. The single-direction augmented impact (subjective add-on to the original shock) would be the relevant one for the purposes of the exercise when used to naively approximate those feedback effects. For clarification purposes, all ideas presented above are summarised in Figure 2.

\section{Interpretation of results}

As with sensitivity analysis, the ultimate aim of scenario analysis is to assess the soundness of the financial system when faced with a stressed economic environment. To do this, as in the cases discussed earlier, the relationship between the determinants of the financial condition of the system under examination and the risk factors affected by the predefined shocks must be found.

Scenario analysis thus examines the impact on profit, expressed in terms of the change in final results (bottom line of the profit and loss account) produced by each stress scenario with respect to that in the baseline scenario, with the required breakdown by major asset and liability grouping and by major profit and loss account line item.

The impact on solvency is also assessed. This is done by analysing the variation in the capital ratio due to the change in the expected loss and coverage thereof by the existing provisions. In particular, the impact is estimated as the change in the capital ratio for each scenario with respect to the capital ratio of the baseline scenario as a result both of the impact on profits and, if applicable, of the possible use of provisions as eligible regulatory capital.

Although the calculation of the impact on profit and solvency seems to be immediate, care must be taken with how this is done when the time horizon exceeds one year. Apart from the mere comparison of annual figures in the baseline and stress scenarios, it is of interest to analyse the effect of the shocks by aggregating the profit figures for each year to give, finally, the cumulative figure for the last year of the time horizon, since this is what best reflects the impact of the stress test on the system's financial condition for each of the scenarios considered.

Accordingly, the impact on profitability is obtained as the difference between the profits calculated under the baseline scenario and those for each of the specified scenarios. Similarly, the impact on solvency is determined by comparing the ratio of the baseline scenario with that of each of the stress scenarios taking the cumulative effect of that comparison on the capital ratio at the end of the predefined time horizon (last year of the period considered). 


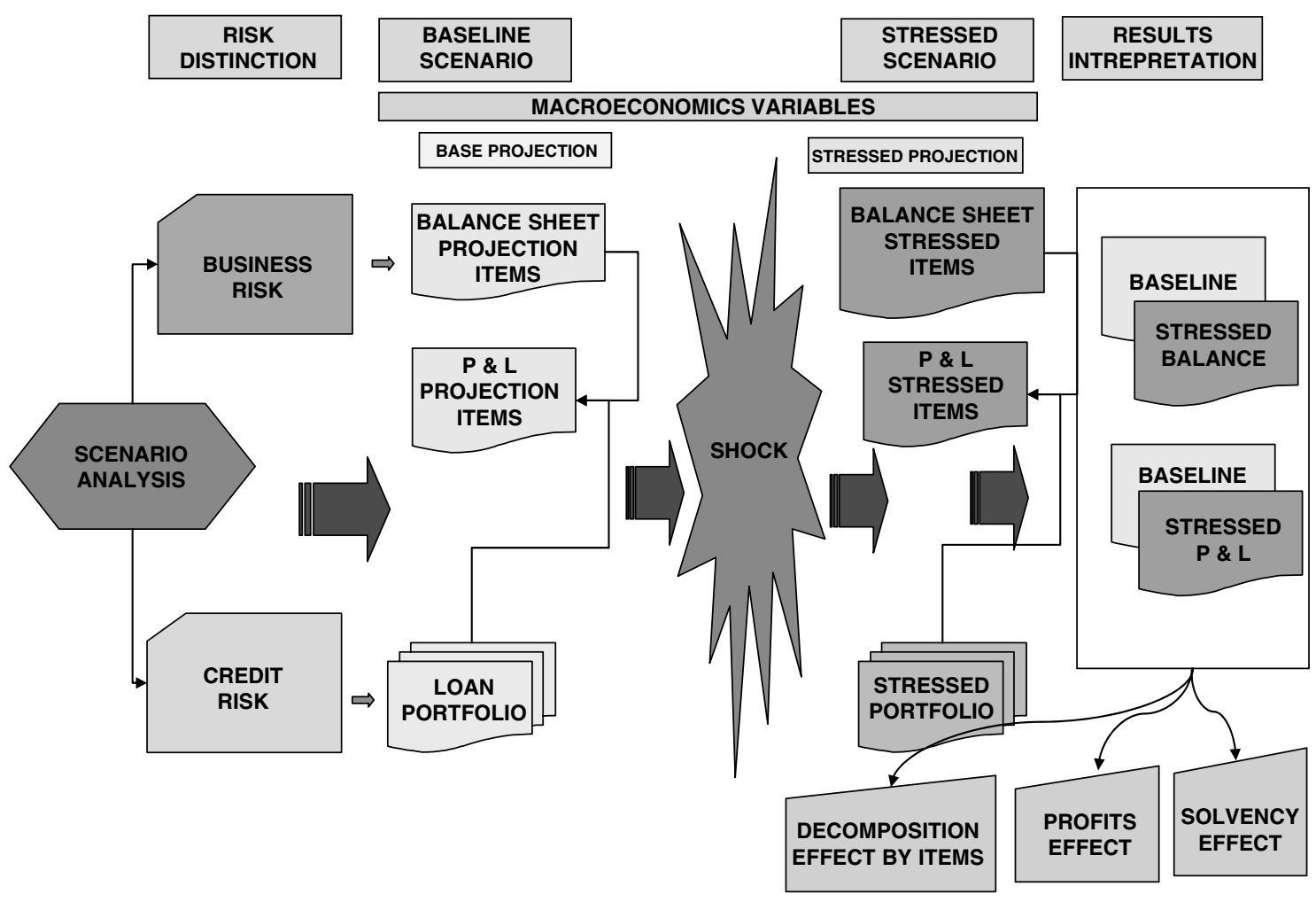

Figure 2 Scenario analysis diagram

A final consideration on stress exercises and how solvency is affected and, in particular, on their growing use to determine the capital adequacy of banks, is in order. The revised structure for the international convergence of capital measurement and capital standards (more commonly known as Basel II) proposes the performance of stress tests to determine whether the minimum requirements set under Pillar I are sufficient. If these tests are considered an additional prerequisite for banks that opt for the advanced approach, stress exercises will take on particular importance, as will the involvement of supervisors in assessing their design, calibration and impact, as stipulated in Pillar II of Basel II.

In principle, the guidelines given in this paper for treating credit risk in scenario stress tests would be valid for gauging whether the capital of banks would be able to absorb a given shock or, for example, whether the capital cushion in excess of the regulatory minimum requirement is sufficient to cope with the related shock.

At first sight it seems clear that the aim of Basel II in the performance of stress tests under Pillar II is to determine whether, in a given scenario, the requirements set by the advanced approach plus the capital buffer that banks may hold are sufficient to absorb a possible adverse shock to a bank's credit exposure. The approach is the same as that followed throughout this paper, that is, determining whether the system or individual institution under examination has sufficient protection (in terms of volume of prudential elements) to cope with a possible adverse scenario without its stability being affected.

However, Basel II also observes that it is advisable to carry out other more specific tests to assess the effect that a given scenario may have on the calculation of regulatory capital 
minimums (Pillar I), or, in other words, to stress the conditions and parameters that determine the required minimum capital.

Irrespective of the final use of stress tests, the key factor in using them properly is the approach that should be adopted for including the shock scenarios in the parameters defining the risk or risks that it is wished to stress. This approach could, to our understanding, follow the steps described above.

\section{CONCLUSION AND AVENUES OF APPLICATION}

The central idea running through this paper is the desirability, for both supervisory authorities and individual institutions, of carrying out stress tests, since they can be of fundamental support for improving risk management in general and a key prudential tool for the supervisor in analysing the risk profile of individual banks and assessing the stability of the financial system as a whole.

Consequently, the design and implementation of stress tests should become an integral part of the usual monitoring plans and procedures that banks have in place to evaluate their robustness and, at the same time, their flexibility in response to extreme but plausible adverse events. The experience gained with the progressive application of this tool could provide constitute a sound basis on which to develop establish broad contingency plans for use in periods of crisis.

Furthermore, financial authorities should also be active in frequent stress testing both at the overall system level and at the level of certain sectors or individual institutions which, given their risk profile, could pose particular concern. This involvement would enable supervisory authorities to identify and properly assess vulnerabilities liable to affect financial stability so as to make their legally entrusted task of risk monitoring and prevention easier to perform.

Lastly, as stress testing methodology is further improved, the technique's full potential as a key element of risk control is realised and it becomes a generally accepted prudential tool, stress tests may allow supervisory authorities to employ a common language. This common language would constitute an additional aid in, for example, the drafting of regulatory guidelines or in agreeing on memoranda of understanding of information exchange among financial authorities of different countries.

Disclaimer: The ideas and opinions expressed in this paper are those of the authors and do not necessarily coincide with those of the Banco de España

\section{ACKNOWLEDGMENTS}

The authors gratefully acknowledge help and useful comments from J.González, M. Ruiz, and F. Vargas. The authors also recognise translation assistance provided by Maxwell Gormann. It goes without saying that remaining errors that may exist in the paper are the authors' responsibility.

\section{References and Notes}

(1) A similar opinion can be found, for example, in Bunn P., Cunningham, A. and Drehmann, M. (2005) 'Stress testing as a tool for assessing systemic risks', Bank of England Financial Stability Review, June; or in Caruana, J. (2005) 'Monetary policy, financial stability and asset prices', Occasional Paper No. 0507, Banco de España, 2005; or finally in López, J.A. (2005) 'Stress tests: Useful complements to financial risk models', Federal Reserve Bank of San Francisco Economic Letter, No. 2005-14, 24 June.

(2) See, Blaschke, W. Jones, M. T. Majnoni, G. and Martínez Peria, S. (2001) 'Stress testing of financial systems: An overview of issues, methodologies, and FSAP experiences', IMF Working Paper, June.

(3) The usual practice followed by most of the countries that have recently tested (assessed) their financial systems.

(4) For example, those relating to credit risk.

(5) Following the terminology used in Sorge, M. (2004) 'Stress-testing financial systems: An 
overview of current methodologies', BIS Working Papers, No. 165.

(6) Given the limited development of the techniques for measuring and managing operational risk, this has not been considered in this paper.

(7) Since the activity of the financial system of many countries is in terms of relative weight, dominated by banks, its soundness can be gauged using a stress test confined to the banking system. This simplification, which does not limit the applicability and usefulness of the exercise described above, is followed in this paper.

(8) Their development and extent of application can be seen in the survey conducted by the Committee on the Global Financial System (2005) 'Stress testing at major financial institutions: Survey results and practice', Bank for International Settlements.

(9) A reference for the calibration and maximum impact of this risk can be found in Basel Committee on Banking Supervision (2004) 'Principles for the management and supervision of interest rate risk', Bank for International Settlements, July.

(10) It seems obvious how to go about stressing parameters such as PD and LGD (raise them by a certain amount). However, EAD should also be subjected to shock, basically in lines of credit. Their use could, in principle, be dependent on cyclical fluctuations in economic activity. Stressing EAD would involve an increase in the drawdowns of those credit lines by borrowers, thereby raising the total credit exposure of banks and thus the risk they incur.

(11) In principle, the amount of impairment losses would be equal to the point-in-time expected losses on the loan portfolio.
(12) See, Financial Services Authority, FSA (2003) 'Liquidity risk in the integrated prudential sourcebook: A quantitative framework', Discussion Paper 24, October.

(13) Additionally, albeit in a very simplistic way, the modelling of different balance sheet items and their contribution (returns) to the final profit figure enables certain types of non-linearities to be introduced into the quantification of the total impact of the shock.

(14) The dependent variable explained by this equation is generally either the system's nonperforming loans ratio, the projected value of which is the basis for determining the volume of provisions to be used given the stress macroeconomic scenario, or directly the volume of provisions (flow or stock).

(15) The probability of default is one of the central concepts for measuring credit risk used by the Basel Committee on Banking Supervision in its publications, particularly that instituting the current framework for international convergence on capital measurement and capital standards. See Basel Committee on Banking Supervision (2005) 'International convergence of capital measurement and capital standards', Bank for International Settlements, updated version, November.

(16) An industry breakdown of borrowers by economic activity would enable the stress test to be enriched by incorporating into it the degree of sensitivity shown by the various economic sectors to changes in macroeconomic variables. Also, a particular industry's impact in terms of an increase in the risk for banking activity and its final impact on the financial condition of the system could be determined. 